\title{
EFEKTIFITAS IMPLEMENTASI PERJANJIAN ASEAN SECTORAL MUTUAL RECOGNITION ARRANGEMENT ON ELECTRICAL AND ELECTRONIC EQUIPMENT (ASEAN EE MRA) BAGI INDONESIA
}

\section{Effectiveness of ASEAN Sectoral Mutual Recognition Arrangement on Electrical and Electronic Equipment (ASEAN EE MRA) Implementation for Indonesia}

\author{
Ari Wibowo dan Suprapto \\ Pusat Penelitian dan Pengembangan Standardisasi, Badan Standardisasi Nasional \\ Gedung 1 BPPT, Lantai 12, JI. M.H.Thamrin no 8, Kebon Sirih, Jakarta Pusat 10340, DKI Jakarta, Indonesia \\ e-mail: ari@bsn.go.id
}

Diterima: 11 Desember 2017, Direvisi: 29 Januari 2018, Disetujui: 30 Januari 2018

\begin{abstract}
Abstrak
Tahun 2002 di Bangkok Thailand, seluruh negara ASEAN menandatangani perjanjian ASEAN EE MRA, perjanjian ini merupakan payung saling pengakuan dan keberterimaan sertifikat hasil uji dan sertifikat produk elektronik dan kelistrikan (EE) antar negara. Ketentuan saling pengakuan dan keberterimaan berdasarkan harmonisasi standar produk EE yang diberlakukan wajib oleh negara anggota ASEAN dengan standar internasional IEC, periode perjanjian ini berlaku tahun 2010. Tujuan penelitian untuk mengetahui seberapa efektif implementasi perjanjian ASEAN EE MRA sejak ditetapkan berdasarkan kesiapan SNI terhadap ASEAN Agreed Standard, Lembaga Penilaian Kesesuaian (LPK) dan pemanfaatan oleh pelaku usaha di Indonesia. Data primer penelitian diperoleh melalui survei terhadap seluruh LPK terdaftar, Produsen produk EE, Forum Grup Discussion (FGD) dengan Designating Body, Regulator, sedangkan data sekunder didapatkan melalui desk studi dengan analisa kualitatif deskriptif dan kuantitatif. Diperoleh hasil bahwa implementasi ASEAN EE MRA terkait harmonisasi standar produk EE sudah efektif dimana Indonesia telah merumuskan 118 SNI dari 119 ASEAN Agreed Version (99,15\%).Seluruh 11 LPK terdaftar telah mempunyai ruang Lingkup $100 \%$ mendukung SNI Wajib. Sedangkan terkait saling pengakuan dan keberterimaan sertifikat hasil uji dan sertifikat produk EE antar negara anggota tidak efektif dimana $100 \%$ produsen belum memanfaatkan skema ASEAN EEMRA.
\end{abstract}

Kata Kunci:ASEAN EEMRA, elektronik, kelistrikan, standar.

\begin{abstract}
In 2002 at Bangkok Thailand, all ASEAN countries signed ASEAN EE MRA agreement which is an umbrella of mutual recognition and acceptance of certificates of test results and certificates electronic and electrical products (EE). Provisions based on harmonization of EE product standards imposed by ASEAN countries with IEC standards, agreement period is valid in 2010. Research objective is to know how effective the implementation of ASEAN EE MRA agreement since set based on the readiness of SNI to ASEAN Agreed Standard, Conformity Assessment Institute (LPK) and utilization by business actors in Indonesia. Primary data were obtained through a survey of all registered LPKs, EE Product Manufacturers, Discussion Group Forums (FGDs) with Designating Body, Regulators, while secondary data were obtained through study desks with qualitative descriptive and quantitative analysis. Result are implementation of ASEAN EE MRA related to the harmonization of EE product standard has been effective where Indonesia has formulated 118 SNI of 119 ASEAN Agreed Version (99.15\%). All 11 registered LPKs have scope 100\% supporting Compulsory SNI. While the mutual recognition and acceptance of certificates of test results and EE product certification among member states is not effective where $100 \%$ of producers have not utilized ASEAN EEMRA scheme.
\end{abstract}

Keywords: ASEAN EEMRA, electronics, electricity, standard.

1.

\section{PENDAHULUAN}

Pemberlakuan kawasan perdagangan bebas di tingkat ASEAN atau ASEAN Free Trade Area (AFTA) dapat menjadi pertanda positif dan negatif bagi negara-negara ASEAN. AFTA bertujuan untuk meningkatkan perdagangan dan investasi antar negara anggota ASEAN. Dengan adanya perdagangan bebas tentu arus perdagangan produk akan semakin pesat di pasar domestik karena peluang pasar semakin terbuka secara luas. Hal ini ditandai dengan meningkatnya volume perdagangan yang signifikan antar negara-negara ASEAN, dengan berbagai jenis produk di pasar domestik akan menjadi pilihan konsumen dengan berbagai harga dan mutu tertentu (Arifin, 2008). Disisi lain menurut Bakhri (2015) yang harus dihadapi oleh 
negara ASEAN adalah membanjirnya produk dengan berbagai mutu karena pemberlakuan standar produk yang berbeda-beda pula dari tiap negara anggota ASEAN dan perlu diterapkan pengawasan mutu sehingga hanya produkproduk yang memenuhi standar yang ditetapkan yang bisa masuk ke pasar domestic dalam mengendalikan produk impor. Menghadapi permasalahan tersebut perlu diciptakan praktik perdagangan yang lebih adil dan terjaminnya perlindungan konsumen dengan melakukan langkah strategis kedepan seperti harmonisasi standar-standar produk dan penilaian kesesuaian antara negara-negara anggota ASEAN. Harmonisasi standar dan penilaian kesesuaian adalah bagian terintegrasi dari penyelenggaraan inisiatif integrasi ekonomi pada tingkat ASEAN (Bambang, 2009). Untuk mewujudkan hal tersebut dibentuklah ASEAN Consultative Committee on Standards and Quality (ACCSQ) dengan harapan dapat mengatasi hambatan teknis perdagangan (Technical Barriers to Trade).

Pada tanggal 5 April 2002 di Bangkok Thailand Negara ASEAN yang terdiri dari Pemerintah Brunei Darussalam, Republik Indonesia, Republik Demokratik Rakyat Laos, Kamboja, Malaysia, Uni Myanmar, Republik Filipina, Republik Singapura, Kerajaan Thailand dan Republik Sosialis Vietnam menandatangani perjanjian ASEAN Sectoral Mutual Recognition Arrangement on Electrical and Electronic Equipment (ASEAN EE MRA). Kegiatan perjanjian dengan melakukan harmonisasi standar produk kelistrikan dan elektronika (EE) antarnegara anggota dengan standar IEC, tujuan perjanjian ini yaitu untuk memfasilitasi perdagangan bebas produk listrik dan elektronik (EE) di wilayah ASEAN melalui pengurangan duplikasi pengujian dan sertifikasi mencakup semua produk EE terhubung langsung atau dihubungkan ke tusuk kontak daya tegangan rendah atau bertenaga baterai, dengan voltase antara 50 dan $1000 \mathrm{~V}$ untuk $\mathrm{AC}$ dan antara 75 dan $1500 \mathrm{~V}$ untuk DC, tidak mencakup perangkat medis dan produk yang sudah termasuk dalam MRA Telekomunikasi ASEAN.

Perjanjian ini merupakan payung saling pengakuan dan keberterimaan sertifikat hasil uji dan sertifikat produk EE antar negara anggota. Ketentuan saling pengakuan dan keberterimaan sertifikat hasil uji dan sertifikat produk ini berdasarkan harmonisasi standar produk EE yang diberlakukan wajib oleh semua negara anggota ASEAN dengan standar internasional IEC. Perbedaan standar produk EE suatu negara anggota dengan standar IEC diijinkan sepanjang terkait dengan kondisi fisik geografis daerahnya dan diinformasikan ke semua negara secara transparan. Mekanisme saling pengakuan dan keberterimaan sertikat hasil uji dan sertifikat produk EE antar negara dilakukan melalui proses penilaian kesesuaian (conformity assessment) oleh lembaga penilaian kesesuaian yaitu laboratorium penguji dan lembaga sertifikasi produk yang terdaftar dan ditunjuk oleh forum JSC EE (ASEAN listed CAB), setiap sertifikat hasil uji dan sertifikat produk yang diterbitkan oleh lembaga penilaian kesesuaian di negara anggota ASEAN yang telah terdaftar di ASEAN dan memiliki kompetensi untuk menguji dan mensertifikasi produk wajib di negara anggota ASEAN, harus diterima tanpa dilakukan pengujian dan sertifikasi ulang. Periode perjanjian ini berlaku sejak tahun 2010 , ditinjau dari aspek ekonomi adanya saling pengakuan dan keberterimaan sertifikat hasil uji dan sertifikat produk menghasilkan peningkatan efisiensi biaya yang cukup besar dan berdampak pada nilai daya saing produk.

\section{TINJAUAN PUSTAKA}

\subsection{ASEAN Electrical Electronic Mutual Recognition Arrangement (ASEAN EE MRA)}

ASEAN EE MRA adalah kesepakatan yang ditandatangani oleh Menteri Ekonomi Negaranegara Anggota ASEAN yang bertujuan untuk memfasilitasi perdagangan bebas peralatan listrik dan elektronik (EE) di wilayah ASEAN melalui pengurangan duplikasi pengujian dan sertifikasi untuk EE yang diproduksi di ASEAN. ASEAN EE MRA mencakup semua EE baru yang dimaksudkan untuk terhubung langsung atau dihubungkan ke tusuk kontak daya tegangan rendah atau bertenaga baterai. Tusuk kontak daya voltase rendah berarti tusuk kontak daya dengan voltase antara 50 dan $1000 \mathrm{~V}$ untuk $A C$ dan antara 75 dan $1500 \mathrm{~V}$ untuk DC.

ASEAN EE MRA tidak mencakup perangkat medis dan produk yang sudah termasuk dalam MRA Telekomunikasi (ASEAN Sekretariat, 2002). Perjanjian ini memungkinkan EE yang diatur jika diuji oleh Laboratorium Pengujian Terdaftar dan/atau disertifikasi oleh Lembaga Sertifikasi Terdaftar di negara anggota pengekspor untuk diterima oleh negara anggota pengimpor tanpa harus menjalani pengujian dan I atau sertifikasi lebih lanjut. Produsen dan traders EE di masing-masing negara ASEAN akan merasa lebih mudah dan lebih murah untuk mengekspor EE mereka ke Negara-negara Anggota ASEAN. Mereka dapat merencanakan 
peluncuran produk baru dengan kepastian yang lebih besar dan waktu yang lebih singkat ke pasar. Mereka dapat menghemat biaya pengujian dan sertifikasi saat EE mereka diuji dan/atau disertifikasi oleh Listed CAB. Hasil penilaian kesesuaian akan diterima di Negara anggota pengimpor tanpa pengujian dan/atau sertifikasi lebih lanjut.

\subsection{Stakeholders ASEAN EE MRA}

(a) Produsen, Pemasok, Importir dan Eksportir yang berniat menempatkan EE di pasar Negara-negara Anggota ASEAN.

(b) Designating Body

Adalah lembaga pemerintah di setiap negara anggota yang memiliki mandat hukum untuk mengambil peran sebagai Designating Body (DB) yang meliputi, antara lain, identifikasi dan pemantauan laboratorium penguji dan/atau lembaga sertifikasi sebagaimana tercantum dalam ASEAN EE MRA.

(c) Badan Akreditasi

Badan Akreditasi Nasional (NAB) di negara anggota ASEAN dan penandatanganan APLAC, dan/atau ILAC Mutual Recognition Arrangement (MRA) untuk laboratorium penguji dan/atau penandatanganan PAC dan/atau IAF Multilateral Recognition Arrangement (MRA) untuk lembaga sertifikasi. Bila tidak ada NAB di negara anggota, Negara Anggota dapat mempertimbangkan untuk menunjuk badan akreditasi di negara anggota ASEAN lainnya yang telah menjadi penandatangan APLAC, ILAC dan PAC, IAF MRA untuk melakukan akreditasi.

(d) Lembaga Penilaian Kesesuaian

Adalah Laboratorium Pengujian dan/atau Lembaga Sertifikasi di negara anggota yang melakukan pengujian dan / atau sertifikasi.

Laboratorium Pengujian dan/atau Lembaga Sertifikasi dengan kompetensi teknis yang diperlukan dapat mengajukan permohonan untuk menjadi Lembaga Penilaian Kesesuaian yang Ditunjuk (CAB) melalui Badan Penunjukan (Designated Body) di masing-masing Negara Anggota untuk melakukan pengujian dan / atau sertifikasi terhadap persyaratan wajib ASEAN Negara anggota.

\subsection{Designating Body (DB)}

(a) Menilai calon lembaga penilaian kesesuaian (CAB) terhadap kriteria penetapan;

(b) Memastikan calon CAB memiliki kompetensi teknis yang relevan untuk menguji atau mengesahkan EEE yang diatur ke persyaratan negara anggota ASEAN sebelum memberinya status sebagai $C A B$ yang ditunjuk/diregister;

(c) Mengirimkan secara tertulis proposal daftar $C A B$ yang ditunjuk melalui perwakilan Joint Sectoral Committee (JSC) untuk pertimbangan JSC terhadap proposal tersebut.

(d) Melakukan pengawasan rutin Kunjungan ke CABs yang terdaftar setelah ditunjuk untuk memastikan bahwa mereka memiliki kompetensi teknisnya; Frekuensi kunjungan semacam itu minimal setahun sekali. Seiring dan bila diperlukan, DB dapat mendelegasikan penilaian $\mathrm{CAB}$ terdaftar ke Badan Akreditasi Nasional (National Accreditation Agency / NAB). Dalam hal ini, $\mathrm{NAB}$ adalah untuk memastikan bahwa $\mathrm{CAB}$ terdaftar memiliki kompetensi teknis yang relevan untuk menguji atau mengesahkan EEE yang diatur ke persyaratan Negaranegara Anggota ASEAN. NAB segera akan melaporkan kepada DB segala ketidaksesuaian atau kegagalan untuk mempertahankan kompetensi sebagai $\mathrm{CAB}$;

(e) Menerbitkan Pemberitahuan Penangguhan dan Pemberitahuan Penarikan ke CAB terdaftar dengan memberikan alasan maksud dari penangguhan dan/atau penarikan tersebut;

(f) Meminta $C A B$ yang terdaftar yang penunjukannya telah ditarik untuk mengembalikan Sertifikat Penunjukannya kepada DB untuk pembatalan;

(g) Menemui $C A B$ terdaftar yang ditangguhkan untuk membahas tindakan perbaikan yang harus dilakukan oleh $\mathrm{CAB}$ yang ditangguhkan;

(h) Memerintahkan $\mathrm{CAB}$ terdaftar yang penunjukannya telah ditangguhkan atau ditarik untuk menghentikan iklan yang berhubungan dengan pencatatannya, dan berhenti membuat iklan lebih lanjut atau perwakilan lainnya terkait penunjukkannya tersebut;

(i) Melarang $\mathrm{CAB}$ terdaftar yang penunjukannya telah ditangguhkan untuk menerbitkan hasil/laporan uji dan sertifikasi selama periode penangguhan;

(j) Menginformasikan kepada JSC EE dan Sekretariat ASEAN untuk menghapus $C A B$ yang telah ditarik penunjukkannya dari daftar $\mathrm{CAB}$ terdaftar. 


\subsection{Persiapan Negara ASEAN dalam ASEAN EE MRA}

Sebuah negara anggota yang ingin berpartisipasi dalam ASEAN EE MRA harus melakukan langkah-langkah berikut: -

Langkah 1 - Pembentukan Infrastruktur Teknis yang Diperlukan

(a) Menetapkan Struktur Pengembangan Standar Nasional

Karena standar merupakan dasar pelaksanaan MRA, oleh karena itu penting bagi negara anggota untuk membentuk struktur Pengembangan Standardisasi Nasional sebagai langkah awal dalam proses berpartisipasi dalam MRA. Sebagai alternatif, negara anggota yang bersangkutan dapat menyatakan penerimaan standar IEC

(b) Menyiapkan Laboratorium Pengujian.

Tidak wajib bagi negara anggota untuk mendirikan laboratorium penguji agar dapat berpartisipasi dalam ASEAN EE MRA. Hal ini karena Pasal 17 (3) ASEAN EE MRA menyatakan bahwa "Para Pihak dapat melakukan jasa pengujian laboratorium dan/atau lembaga sertifikasi pihak lain untuk melakukan kegiatan penilaian kesesuaian yang diperlukan, jika tidak memiliki fasilitas sendiri untuk melakukan hal tersebut". Namun, jika negara anggota bermaksud untuk mendirikan laboratorium pengujian, maka harus diakreditasi berdasarkan ISO/IEC 17025: 2005, atau CBTL berdasarkan skema IECEE CB akreditasi ini dapat diperoleh baik dari skema akreditasi Nasional negara anggota atau dapat memperoleh akreditasi dari skema akreditasi negara anggota lainnya.

(c) Penyiapan sistem sertifikasi

Berdasarkan ketentuan Pasal 17 (3) ASEAN EE MRA, ini juga memungkinkan negaranegara anggota untuk melibatkan layanan dari pihak lain jika mereka tidak memiliki fasilitas sendiri untuk melakukannya. Namun, jika telah dibentuk lembaga sertifikasi harus diakreditasi sesuai dengan persyaratan ISO/IEC 65: 1996, atau menjadi anggota Skema IECEE CB;

(d) Penyusunan Skema Akreditasi Nasional Skema ini dapat diatur jika negara-negara anggota ingin memiliki akreditasi mereka sendiri untuk berpartisipasi dalam MRA. Namun laboratorium / lembaga sertifikasi (CAB) juga dapat memperoleh pengakuan melalui Skema IECEE CB atau diakreditasi oleh badan akreditasi nasional anggota negara lainnya.

Langkah 2 - Persiapan Aplikasi

(a) Penunjukan Designating Body

Negara-negara anggota yang ingin berpartisipasi dalam ASEAN EE MRA harus menunjuk "Designating Body" dengan tanggung jawab untuk mengidentifikasi dan memantau laboratorium penguji dan/atau lembaga sertifikasi. Designating Body ini harus memenuhi persyaratan sebagaimana dimaksud dalam Pasal 5 ASEAN EE MRA seperti yang ditunjukkan di bawah ini:

(i) Negara anggota ASEAN akan memastikan bahwa Designating Body memiliki wewenang dan kompetensi di wilayah masing-masing untuk melaksanakan keputusan yang dipersyaratkan dalam MRA sektoral EE ini.

(ii) Designating Body akan memastikan bahwa Laboratorium Pengujian dan / atau Lembaga Sertifikasi yang diidentifikasi oleh mereka dan tercantum dalam MRA sektoral EE ini mampu dan tetap dapat menilai kesesuaian produk atau proses dengan baik, sebagaimana berlaku, dan sebagaimana tercakup dalam MRA Sektoral EE. Designating Body akan memelihara pemantauan Laboratorium Pengujian dan / atau Lembaga Sertifikasi yang tercantum dalam MRA Sektoral EE

(iii) Designating Body juga dapat menunjuk badan akreditasi untuk mengakreditasi Laboratorium Pengujian dan/atau Lembaga Sertifikasi sambil tetap bertanggung jawab penuh sebagai Badan Penunjuk di bawah sektoral ini.

(iv) Designating Body akan berkonsultasi seperlunya dengan rekan-rekan mereka di pihak lain, untuk memastikan pemeliharaan kepercayaan dalam prosedur penilaian kesesuaian. Konsultasi ini dapat mencakup partisipasi bersama dalam audit / pemeriksaan yang berkaitan dengan kegiatan penilaian kesesuaian atau penilaian lain terhadap Laboratorium Pengujian dan atau Lembaga Sertifikasi yang tercantum dalam sektor EE ini.

(v) Designating Body akan berkonsultasi, jika perlu, dengan Otoritas Pengaturan yang relevan untuk memastikan bahwa semua persyaratan wajib yang diidentifikasi dan ditangani secara memuaskan. 
(b) Pembentukan Contact Point Negara anggota yang ingin berpartisipasi dalam MRA harus mengidentifikasi "Contact Point" sebagaimana didefinisikan dalam MRA.

(c) Dokumentasi untuk Partisipasi Negara-negara anggota yang ingin berpartisipasi dalam ASEAN EE MRA harus mengisi Formulir Pemberitahuan.

$C A B$ dapat diakreditasi oleh NAB berdasarkan standar berikut:

(i) ISO/IEC 17025: 2005 untuk laboratorium penguji

(ii) ISO/IEC 65: 1996 untuk lembaga sertifikasi produk

Akreditasi tersebut harus sesuai dengan jenis produk dan peraturan teknis yang sesuai dengan yang ditentukan. NAB yang melakukan akreditasi harus menjadi penandatangan APLAC, dan/atau ILAC MRA untuk laboratorium penguji dan / atau penandatangan PAC dan/atau IAF MLA untuk lembaga sertifikasi yang mendapat evaluasi dari rekan NAB anggota APLAC/ILAC atau PAC/IAF atas kompetensi badan akreditas (NAB).

\section{$2.5 \quad$ Efektivitas}

Definisi efektifitas adalah suatu ukuran yang menyatakan seberapa jauh target (kuantitas, kualitas dan waktu) telah tercapai (Hidayat, 1996). Efektivitas merupakan unsur pokok untuk mencapai tujuan atau sasaran yang telah ditentukan di dalam setiap organisasi, kegiatan ataupun program. Disebut efektif apabila tercapai tujuan ataupun sasaran seperti yang telah ditentukan. Tingkat efektivitas juga dapat diukur dengan membandingkan antara rencana yang telah ditentukan dengan hasil nyata yang telah diwujudkan. Namun, jika usaha atau hasil pekerjaan dan tindakan yang dilakukan tidak tepat sehingga menyebabkan tujuan tidak tercapai atau sasaran yang diharapkan, maka hal itu dikatakan tidak efektif.

\section{METODE PENELITIAN}

Pengumpulan data primer dilakukan dengan survei lapangan ke seluruh (sensus) Lembaga Penilaian Kesesuaian (LPK) yang terdaftar di Designating Body (DB), yaitu : Balai Pengujian Mutu Barang (BPMB) Kemendag, PT. Hartono Istana Teknologi (HIT), PT. Panasonic Manufacturing Indonesia, Balai Besar Barang dan Bahan Teknik (B4T), PT. Qualis Indonesia, dan Sucofindo Laboratory. Lembaga Sertifikasi Produk (LSPro) yaitu: Sucofindo International
Certification Service (SICS), TUV Rheinland Indonesia, Balai Sertifikasi Industri (BSI), TUV Nord Indonesia, Balai Sertifikasi Kemendag (LSPro PPMB). Sedangkan data pelaku usaha (produsen) produk EE dilakukan berdasarkan purposive sampling. Selain survei lapangan, data primer juga didapat melalui Focus Group Discussion (FGD), sedangkan data sekunder didapatkan dengan studi pustaka. Pengolahan dan analisis data dilakukan dengan deskriptif kualitatif (Iskandar 2008).

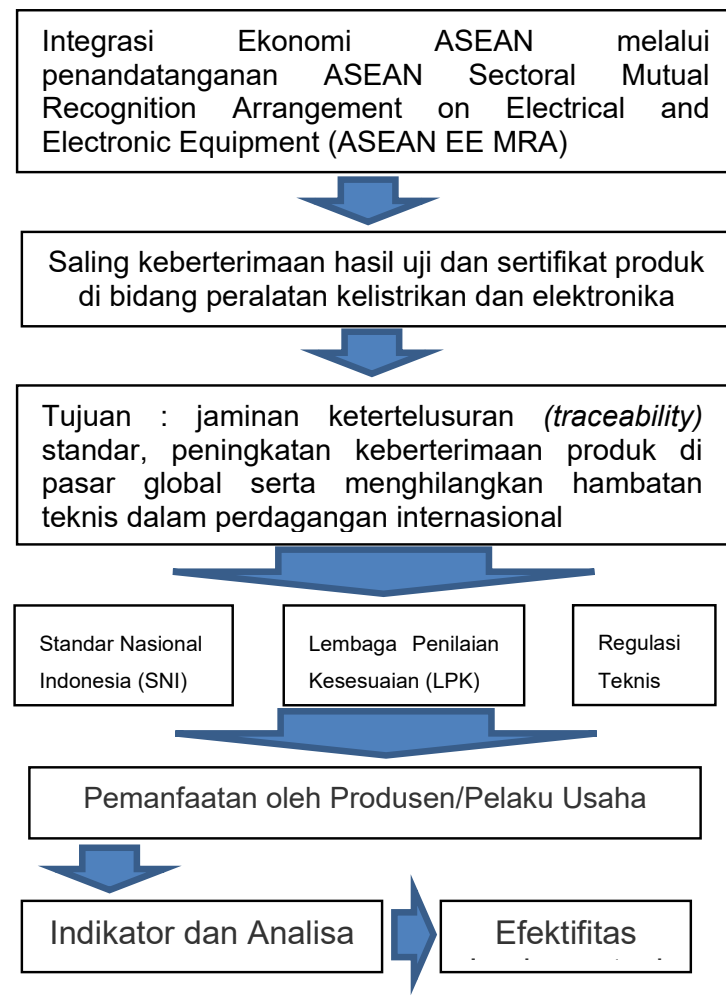

Gambar 1 Kerangka pikir penelitian.

\section{HASIL DAN PEMBAHASAN}

\subsection{Ekspor Impor Produk Elektronik dan Kelistrikan Indonesia-ASEAN}

Ekspor adalah salah satu sektor perekonomian yang memegang peranan penting melalui perluasan pasar antara beberapa negara, di mana dapat mengadakan perluasan dalam suatu industri, sehingga mendorong dalam industri lain, selanjutnya mendorong sektor lainnya dari perekonomian (Baldwin, 2005), makna inti dari ekspor adalah kegiatan menjual barang ke luar negeri dengan tujuan mencari keuntungan baik bagi perusahaan, individu, maupun bagi negara.

Impor adalah kegiatan memasukkan barang ke dalam daerah pabean. Transaksi impor adalah 
perdagangan dengan cara memasukkan barang dari luar negeri ke dalam daerah pabean Indonesia dengan mematuhi ketentuan peraturan perudang-undangan yang berlaku (Tandjung, 2011).

Tabel 1 Ekspor Industri Komputer, Barang Elektronik, Peralatan Listrik.

\begin{tabular}{|c|c|c|c|c|}
\hline \multirow{3}{*}{ No } & \multirow{3}{*}{$\begin{array}{l}\text { Negara } \\
\text { Tujuan }\end{array}$} & \multicolumn{3}{|c|}{ Tahun } \\
\hline & & 2014 & 2015 & 2016 \\
\hline & & \multicolumn{3}{|c|}{ Nilai dalam Juta US Dollar } \\
\hline 1 & Malaysia & 352.119 & 353.567 & 383.485 \\
\hline 2 & Singapura & $2,898,484$ & $2,249,324$ & $2,114,942$ \\
\hline 3 & Thailand & 443.396 & 404.037 & 368.845 \\
\hline 4 & Philiphina & 223.161 & 153.489 & 168.797 \\
\hline 5 & Vietnam & 155.644 & 203.338 & 160.372 \\
\hline 6 & Kamboja & 1081 & 2632 & 2490 \\
\hline 7 & Laos & 0 & 11 & 80 \\
\hline 8 & Brunei & 8.360 & 8.438 & 2.255 \\
\hline$\overline{9}$ & Myanmar & 15.180 & 13.956 & 12.575 \\
\hline
\end{tabular}

Berdasarkan analisa data ekspor impor produk elektronik dan kelistrikan antara Indonesia dan ASEAN diolah dari Kementerian Perindustrian diketahui bahwa Indonesia hanya mengalami surplus dengan negara Laos, Brunei dan Myanmar, sedangakan dengan 6 (enam) negara ASEAN lainnya yang terdiri dari Malaysia, Singapura, Thailand, Philiphina, Vietnam dan Kamboja tidak surplus (Tabel 1 dan Tabel 2).

Tabel 2 Impor Industri Komputer, Barang Elektronik, Peralatan Listrik.

\begin{tabular}{|c|c|c|c|c|}
\hline \multirow{3}{*}{ Nc } & \multirow{3}{*}{ Dari Negara } & \multicolumn{3}{|c|}{ Tahun } \\
\hline & & 2014 & 2015 & 2016 \\
\hline & & \multicolumn{3}{|c|}{ Nilai dalam Juta US Dollar } \\
\hline 1 & Malaysia & 957.497 & 761.484 & 728.853 \\
\hline 2 & Singapura & $2,571,7272$ & $, 177,806$ & $2,119,095$ \\
\hline 3 & Thailand & 797.670 & 696.948 & 775.976 \\
\hline 4 & Philiphina & 233.713 & 227.524 & 233.392 \\
\hline 5 & Vietnam & 1.389 .1931 & .217 .037 & 1.317 .641 \\
\hline 6 & Kamboja & 1181 & 3766 & 2711 \\
\hline 7 & Laos & 9 & 0 & 49 \\
\hline & Brunei & 482 & 1859 & 477 \\
\hline 9 & Myanmar & 228 & 572 & 223 \\
\hline
\end{tabular}

(sumber: Kementerian Perindustrian, 2016., diolah).

\subsection{Kesiapan Standar, LPK dan Penambahan Ruang Lingkup}

Perjanjian ASEAN EE MRA menyepakati bahwa harmonisasi standar produk kelistrikan dan elektronika yang diberlakukan wajib oleh semua negara ASEAN dengan standar internasional IEC (International Electrotechnical Commission), digunakan sebagai dasar ketentuan saling pengakuan dan keberterimaan sertifikat hasil uji. Perbedaan standar produk kelistrikan dan elektronika suatu negara anggota ASEAN dengan standar IEC diijinkan sepanjang terkait dengan kondisi fisik geografis daerahnya dan diinformasikan ke semua negara ASEAN secara transparan.

Hasil identifikasi melalui Sistem Informasi SNI (BSN SISNI, 2016) dan analisa data terdapat 119 standar IEC produk EE yang disepakati untuk di harmonisasi, sampai dengan September 2017 Indonesia telah mengadopsi sebanyak 118 standar IEC menjadi Standar Nasional Indonesia, artinya sekitar 99,15\% telah tersedia SNI produk EE yang harmonis dengan kesepakatan ASEAN EE MRA (Gambar 2).

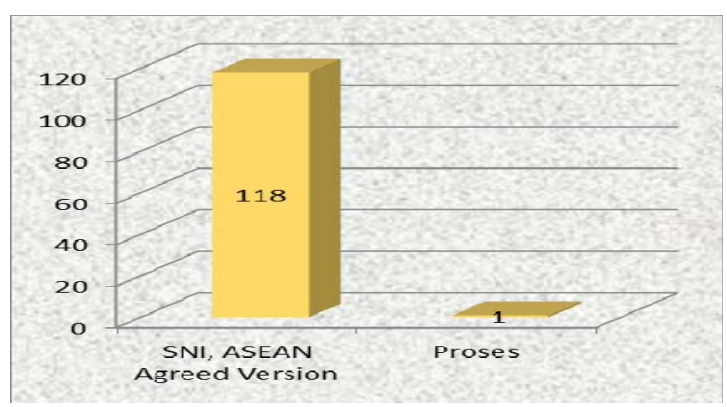

Gambar 2 SNI produk EE berdasarkan Agreed Standar Version.

Dari 118 SNI yang telah harmonis, terdapat 22 (dua puluh dua) produk EE yang terdapat di 26 (dua puluh enam) SNI EE yang telah diwajibkan oleh Pemerintah Indonesia melalui Peraturan Menteri Perindustrian dan Peraturan Menteri ESDM (Tabel 3).

Tabel 3 SNI Produk EE yang Diwajibkan melalui Peraturan Menteri Perindustrian dan ESDM.

\begin{tabular}{llll}
\hline No & \multicolumn{3}{c}{ STANDARDS } \\
\cline { 2 - 4 } & $\begin{array}{c}\text { Domestic } \\
\text { Standards }\end{array}$ & $\begin{array}{c}\text { Relevant } \\
\text { International } \\
\text { Standards }\end{array}$ & $\begin{array}{c}\text { Product type or } \\
\text { grouping }\end{array}$ \\
\hline 1 & SNI 04- & $\begin{array}{l}\text { IEC 60064 } \\
\text { Ed.6 (1993- } \\
\text { 3560-1994 }\end{array}$ & Incandescent lamps \\
& & 12) \\
\hline
\end{tabular}


Efektifitas Implementasi Perjanjian Asean Sectoral Mutual Recognition Arrangement on Electrical and Electronic Equipment (ASEAN EE MRA) Bagi Indonesia (Ari Wibowo dan Suprapto)

\begin{tabular}{|c|c|c|c|c|c|c|c|}
\hline \multirow[t]{2}{*}{ No } & \multicolumn{3}{|c|}{ STANDARDS } & \multirow[t]{2}{*}{ No } & \multicolumn{3}{|c|}{ STANDARDS } \\
\hline & $\begin{array}{l}\text { Domestic } \\
\text { Standards }\end{array}$ & $\begin{array}{c}\text { Relevant } \\
\text { International } \\
\text { Standards }\end{array}$ & $\begin{array}{l}\text { Product type or } \\
\text { grouping }\end{array}$ & & $\begin{array}{l}\text { Domestic } \\
\text { Standards }\end{array}$ & $\begin{array}{c}\text { Relevant } \\
\text { International } \\
\text { Standards }\end{array}$ & $\begin{array}{l}\text { Product type or } \\
\text { grouping }\end{array}$ \\
\hline \multirow[t]{3}{*}{2} & $\begin{array}{l}\text { SNI 04- } \\
6504-2001\end{array}$ & $\begin{array}{l}\text { IEC } 60968 \\
\text { Ed.1.0 (1988- } \\
11)\end{array}$ & $\begin{array}{l}\text { Self-ballast lamp for } \\
\text { general lighting } \\
\text { service }\end{array}$ & & $\begin{array}{l}\text { SNI } 4- \\
6973.1- \\
2005\end{array}$ & $\begin{array}{l}\text { IEC 60598-1 } \\
(2003)\end{array}$ & $\begin{array}{l}\text { Luminaires - Part 1: } \\
\text { General } \\
\text { requirements and }\end{array}$ \\
\hline & \multirow{2}{*}{$\begin{array}{l}\text { SNI IEC } \\
60969: 200 \\
9 \\
\end{array}$} & \multirow{2}{*}{$\begin{array}{l}\text { IEC } \\
60969: 2001\end{array}$} & & & & & \\
\hline & & & & \multirow[t]{2}{*}{9} & \multirow{2}{*}{$\begin{array}{l}\text { SNI } 4 \text { - } \\
6973.2 .1- \\
2005\end{array}$} & \multirow{2}{*}{$\begin{array}{l}\text { IEC 60598-2-1 } \\
(1979)\end{array}$} & \multirow{2}{*}{$\begin{array}{l}\text { Luminaires - Part 2- } \\
\text { 1: Particular } \\
\text { requirements - Fixed } \\
\text { general purpose } \\
\text { luminaires }\end{array}$} \\
\hline \multirow[t]{2}{*}{3} & \multirow[t]{2}{*}{$\begin{array}{l}\text { SNI 04- } \\
\text { 3892.1-2006 }\end{array}$} & \multirow[t]{2}{*}{$\begin{array}{l}\text { IEC 60884-1 } \\
(2002-06)\end{array}$} & \multirow{2}{*}{$\begin{array}{l}\text { Plugs and socket- } \\
\text { outlets for household } \\
\text { and similar } \\
\text { purposes. Part } 1 \text { : } \\
\text { General requirement }\end{array}$} & & & & \\
\hline & & & & 10 & SNI 4 - & IEC 60598-2-2 & $\begin{array}{l}\text { Luminaires - Part 2- } \\
\text { 2: Particular }\end{array}$ \\
\hline \multirow[t]{2}{*}{4} & \multirow[t]{2}{*}{$\begin{array}{l}\text { SNI 04- } \\
6203.1-2006\end{array}$} & \multirow[t]{2}{*}{$\begin{array}{l}\text { IEC 60669-1 } \\
(2000)\end{array}$} & \multirow{2}{*}{$\begin{array}{l}\text { Switches for } \\
\text { household } \\
\text { installations and } \\
\text { similar fixed electric. } \\
\text { Part 1: General } \\
\text { requirements } \\
\end{array}$} & & $\begin{array}{l}6973.2 .2- \\
2005\end{array}$ & (1997) & $\begin{array}{l}\text { requirements - } \\
\text { Recessed } \\
\text { luminaires }\end{array}$ \\
\hline & & & & 11 & $\begin{array}{l}\text { SNI } 4 \text { - } \\
6973.2 .3-\end{array}$ & $\begin{array}{l}\text { IEC 60598-2-3 } \\
(2002)\end{array}$ & $\begin{array}{l}\text { Luminaires - Part 2- } \\
\text { 3: Particular } \\
\text { requirements - }\end{array}$ \\
\hline \multirow[t]{4}{*}{5} & \multirow{4}{*}{$\begin{array}{l}\text { SNI 04- } \\
6507.1- \\
2002 \\
\text { SNI 04- } \\
6507.1- \\
2002 / \text { Amd } \\
1.2006\end{array}$} & \multirow[t]{4}{*}{$\begin{array}{l}\text { IEC 60898-1 } \\
(2003)\end{array}$} & \multirow{4}{*}{$\begin{array}{l}\text { Circuit breakers for } \\
\text { over current } \\
\text { protection for } \\
\text { household and } \\
\text { similar installation. } \\
\text { Part } 1 \text { : Circuit } \\
\text { breaker for a.c } \\
\text { operated }\end{array}$} & & 2005 & & $\begin{array}{l}\text { Luminaires for road } \\
\text { and street lighting }\end{array}$ \\
\hline & & & & 12 & SNI 4 - & IEC 60598-2-5 & Luminaires - Part 2- \\
\hline & & & & & $\begin{array}{l}6973.2 .5- \\
2005\end{array}$ & (1998): & $\begin{array}{l}\text { 5: Particular } \\
\text { requirements - } \\
\text { Floodlights }\end{array}$ \\
\hline & & & & 13 & SNI 04- & IEC 60086-1 & Primary Battery - part \\
\hline \multirow[t]{3}{*}{6} & \multirow{3}{*}{$\begin{array}{l}\text { SNI 04- } \\
6292.2 .80- \\
2006\end{array}$} & \multirow{3}{*}{$\begin{array}{l}\text { IEC 60335-2- } \\
80(2004-03)\end{array}$} & \multirow{3}{*}{$\begin{array}{l}\text { Electrical appliances } \\
\text { for household } \\
\text { usages and other } \\
\text { similar types of } \\
\text { safety products; Part } \\
\text { 2-80. Special } \\
\text { requirements for } \\
\text { electric fan }\end{array}$} & & $\begin{array}{l}2051.1- \\
2004\end{array}$ & & \\
\hline & & & & & $\begin{array}{l}\text { SNI 04- } \\
2051.2- \\
2004\end{array}$ & $\begin{array}{l}\text { IEC 60086-2 } \\
(2000)\end{array}$ & $\begin{array}{l}\text { Primary Battery - part } \\
\text { 2: Electrical and } \\
\text { Physical } \\
\text { Requirement }\end{array}$ \\
\hline & & & & \multirow[t]{2}{*}{14} & \multirow{2}{*}{$\begin{array}{l}\text { SNI 04- } \\
6629.3- \\
2006\end{array}$} & \multirow[t]{2}{*}{$\begin{array}{l}\text { IEC 60227- } \\
3(1997-11)\end{array}$} & \multirow{2}{*}{$\begin{array}{l}\text { PVC insulated } \\
\text { cables with a rated } \\
\text { voltage up to } \\
450 / 750 \mathrm{~V} \text { - Part } 3 \text { : } \\
\text { Non-sheated cables } \\
\text { for fixed wiring }\end{array}$} \\
\hline \multirow[t]{2}{*}{7} & $\begin{array}{l}\text { SNI 04- } \\
6959.1- \\
2003 \\
\end{array}$ & $\begin{array}{l}\text { IEC 61347-1 } \\
(2000-10)\end{array}$ & $\begin{array}{l}\text { Lamp controlgears - } \\
\text { Part 1: General and } \\
\text { safety requirements }\end{array}$ & & & & \\
\hline & $\begin{array}{l}\text { SNI 04- } \\
6959.2 .3- \\
2003\end{array}$ & $\begin{array}{l}\text { IEC 61347-2-3 } \\
(2000-10)\end{array}$ & $\begin{array}{l}\text { Lamp controlgears - } \\
\text { Part 2-3: Particular } \\
\text { requirements for a.c. } \\
\text { supplied electronic } \\
\text { ballasts for } \\
\text { fluorescent lamps }\end{array}$ & 15 & $\begin{array}{l}\text { SNI 04- } \\
6629.4- \\
2006\end{array}$ & $\begin{array}{l}\text { IEC 60227- } \\
4(1997-12)\end{array}$ & $\begin{array}{l}\text { PVC insulated } \\
\text { cables with a rated } \\
\text { voltage up to } \\
450 / 750 \mathrm{~V}-\text { Part } 4 \text { : } \\
\text { Sheated cables for } \\
\text { fixed wiring }\end{array}$ \\
\hline \multirow[t]{5}{*}{8} & $\begin{array}{l}\text { SNI } 4 \text { - } \\
6956.1- \\
2003\end{array}$ & $\begin{array}{l}\text { IEC 61008-1 } \\
(1996-12)\end{array}$ & $\begin{array}{l}\text { Residual current } \\
\text { operated circuit - } \\
\text { breakers without } \\
\text { integral overcurrent } \\
\text { protection for }\end{array}$ & 16 & $\begin{array}{l}\text { SNI 04- } \\
6629.5- \\
2006\end{array}$ & $\begin{array}{l}\text { IEC 60227- } \\
5(2003-07)\end{array}$ & $\begin{array}{l}\text { PVC insulated } \\
\text { cables with a rated } \\
\text { voltage up to } \\
450 / 750 \mathrm{~V} \text { - Part } 5: \\
\text { Flexible cables }\end{array}$ \\
\hline & & & $\begin{array}{l}\text { household and } \\
\text { similar uses (RCCB) - } \\
\text { Part 1: General rules }\end{array}$ & 17 & $\begin{array}{l}\text { SNI 04- } \\
\text { 6292.2.41- }\end{array}$ & $\begin{array}{l}\text { IEC 60335-2- } \\
41(2002-10)\end{array}$ & $\begin{array}{l}\text { Safety of household } \\
\text { and similar electrical }\end{array}$ \\
\hline & $\begin{array}{l}\text { SNI 04- } \\
6956.2 .1- \\
2005\end{array}$ & $\begin{array}{l}\text { IEC 61008-2-1 } \\
(1990-12)\end{array}$ & $\begin{array}{l}\text { Residual current } \\
\text { operated circuit- } \\
\text { breakers without }\end{array}$ & & & & $\begin{array}{l}\text { appliances - Part 2- } \\
41 \text { : Particular } \\
\text { requirements for } \\
\text { pumps }\end{array}$ \\
\hline & & & $\begin{array}{l}\text { integral overcurrent } \\
\text { protection for } \\
\text { household and } \\
\text { similar uses } \\
\text { (RCCB's) - Part 2-1: } \\
\text { Applicability of the }\end{array}$ & 18 & $\begin{array}{l}\text { SNI 04- } \\
6292.2 .3- \\
2003\end{array}$ & $\begin{array}{l}\text { IEC 60335-2- } \\
3(2002-03)\end{array}$ & $\begin{array}{l}\text { Household and } \\
\text { similar electrical } \\
\text { appliances - Safety } \\
\text { - Part 2-3: Particular } \\
\text { requirements for } \\
\text { electric irons }\end{array}$ \\
\hline & & & $\begin{array}{l}\text { general rules to } \\
\text { RCCB's functionally } \\
\text { independent of line } \\
\text { voltage }\end{array}$ & 19 & $\begin{array}{l}\text { SNI 04- } \\
6253-2003\end{array}$ & $\begin{array}{l}\text { IEC 60065 } \\
(2001-12)\end{array}$ & $\begin{array}{l}\text { Audio, video and } \\
\text { similar electronic } \\
\text { apparatus - Safety } \\
\text { requirements }\end{array}$ \\
\hline
\end{tabular}




\begin{tabular}{|c|c|c|c|}
\hline \multirow[t]{2}{*}{ No } & \multicolumn{3}{|c|}{ STANDARDS } \\
\hline & $\begin{array}{l}\text { Domestic } \\
\text { Standards }\end{array}$ & $\begin{array}{c}\text { Relevant } \\
\text { International } \\
\text { Standards }\end{array}$ & $\begin{array}{l}\text { Product type or } \\
\text { grouping }\end{array}$ \\
\hline 20 & $\begin{array}{l}\text { SNI IEC } \\
60335-2- \\
40: 2009\end{array}$ & $\begin{array}{l}\text { IEC 60335-2-40 } \\
\text { Ed } 4.2 \text { (2005- } \\
07)\end{array}$ & $\begin{array}{l}\text { Household and } \\
\text { similar electrical } \\
\text { appliances - Safety - } \\
\text { Part 2-40: Particular } \\
\text { requirements for } \\
\text { electrical heat } \\
\text { pumps, air- } \\
\text { conditioners and } \\
\text { dehumidifiers } \\
\end{array}$ \\
\hline 21 & $\begin{array}{l}\text { SNI IEC } \\
60335-2- \\
24: 2009\end{array}$ & $\begin{array}{l}\text { IEC 60335-2- } \\
24 \text { Ed 6.1 } \\
(2005-04)\end{array}$ & $\begin{array}{l}\text { Household and } \\
\text { similar electrical } \\
\text { appliances - Safety - } \\
\text { Part 2-24: Particular } \\
\text { requirements for } \\
\text { refrigerating } \\
\text { appliances, ice- } \\
\text { cream appliances } \\
\text { and ice makers }\end{array}$ \\
\hline 22 & $\begin{array}{l}\text { SNI IEC } \\
60335-2- \\
7: 2009\end{array}$ & $\begin{array}{l}\text { IEC 60335-2- } \\
7(2004-11)\end{array}$ & $\begin{array}{l}\text { Household and } \\
\text { similar electrical } \\
\text { appliances - Safety - } \\
\text { Part 2-7: Particular } \\
\text { requirements for } \\
\text { washing machines }\end{array}$ \\
\hline
\end{tabular}

Hingga September 2017 terdapat 11 Lembaga Penilaian Kesesuaian (LPK) yang terdaftar di Designating Body (DB), Laboratorium Uji yaitu: Balai Pengujian Mutu Barang (BPMB) Kemendag, PT. Hartono Istana Teknologi (HIT), PT. Panasonic Manufacturing Indonesia, Balai Besar Barang dan Bahan Teknik (B4T), PT. Qualis Indonesia, dan Sucofindo Laboratory. Lembaga Sertifikasi Produk (LSPro) yaitu: Sucofindo International Certification Service (SICS), TUV Rheinland Indonesia, Balai Sertifikasi Industri (BSI), TUV Nord Indonesia, Balai Sertifikasi Kemendag (LSPro PPMB), dan 5 Lembaga Pengujian yang berpotensi untuk listing.

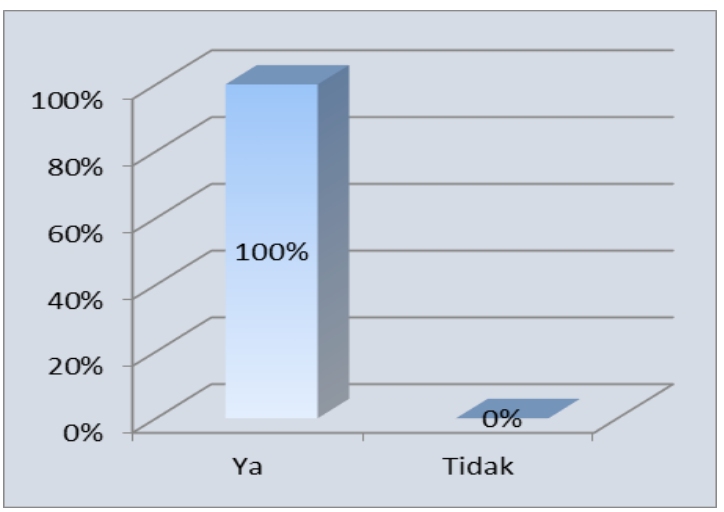

Gambar 3 Rencana LPK menambah ruang lingkup produk EE.
Dari 11 Laboratorium Uji dan Lembaga Sertifikasi yang terdaftar, seluruh ruang lingkup yang dimiliki telah $100 \%$ mendukung SNI Wajib. Hasil kuesioner terhadap seluruh LPK tersebut menunjukan bahwa LPK akan menambah ruang lingkup untuk produk-produkelektronik dan kelistrikan baik yang wajib maupun yang sukarela.

\subsection{Pengajuan Listing Conformity Assessment Body}

Laboratorium Pengujian dan/atau Lembaga Sertifikasi dengan kompetensi teknis yang diperlukan dapat mengajukan permohonan untuk menjadi LPK yang ditunjuk (CAB) melalui Badan Penunjukan (Designated Body) di masingmasing negara Anggota untuk melakukan pengujian dan atau sertifikasi terhadap persyaratan wajib ASEAN negara anggota.

Berdasarkan hasil survey dan wawancara terhadap seluruh LPK yang terdaftar terhadap hambatan dan tidak ada hambatan ketika melakukan proses pendaftaran, kontestasi hingga mendapatkan sertifikat didapat bahwa $67 \%$ LPK mempunyai hambatan berupa penerbitan terjemahan sertifikat akreditasi dari KAN lama, sedangkan $33 \%$ LPK tidak mempunyai hambatan ketika pengajuan proses listing (Gambar 4).

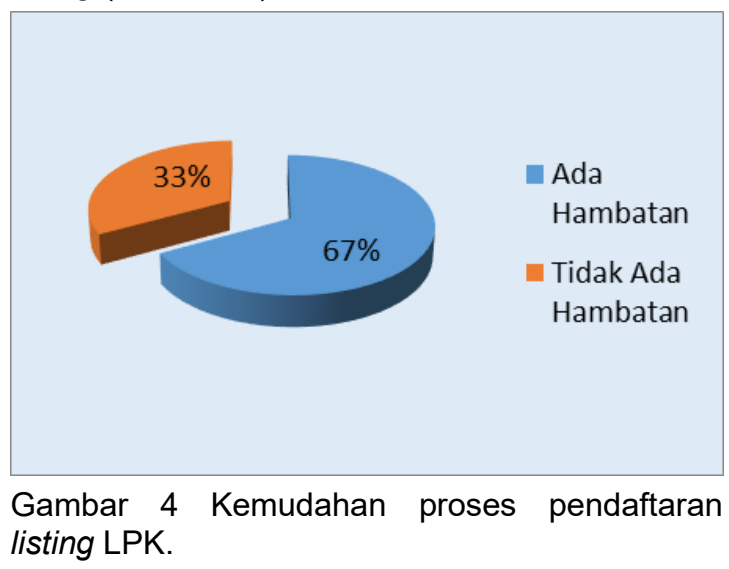

\subsection{Pemanfaatan Skema ASEAN EE MRA oleh Industri dan LPK}

Berdasarkan hasil survei dan wawancara terhadap 8 (delapan) produsen produk elektronik dan kelistrikan terhadap efektifitas perjanjian ASEAN EE MRA, 100\% menjawab belum efektif (Gambar 5), dikarenakan $83 \%$ produsen belum mengetahui dan menggunakan skema ASEAN EE MRA, adapun $17 \%$ sudah mengetahui skema tersebut namun mengalami penolakan ketika proses listing ruang lingkup produk EE yang di 
produksi dikarenakan regulasi di negara tujuan ekspor tidak sama dengan regulasi di Indonesia.

Berdasarkan hasil identifikasi dan analisis data, dari 9 (sembilan) negara ASEAN, setidaknya ada 4 (empat) negara yang mempunyai regulasi yang perlu penyesuaian dengan Indonesia, negara tersebut yaitu: Singapura, Malaysia, Thailand, Philipina.

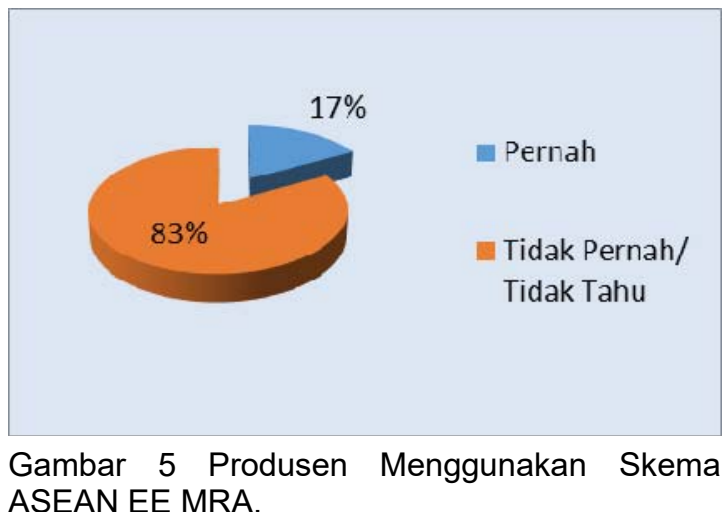

ASEAN EE MRA.

Implementasi ASEAN EE MRA yang telah sepakati tahun 2010, namun dalam pelaksanaan integrasi pasar tunggal dan basis produksi ASEAN ternyata tidak cukup berdasarkan pada harmonisasi standar produk semata, agar dapat berjalan efektif terdapat satu tahapan lagi yang memiliki peran sangat penting dan menentukan, yaitu harmonisasi regulasi. Ketentuan saling pengakuan dan keberterimaan sertifikat hasil uji yang diterbitkan oleh lembaga penilaian kesesuaian terdaftar dan ditunjuk oleh JSC EEE, tidak akan berjalan dengan efektif jika regulasi yang berlaku di masing-masing negara ASEAN tidak mendukung dan kompatibel.

Terkait masalah regulasi di atas, JSC EEE telah menetapkan suatu perjanjian baru yang dinamakan ASEAN Harmonized Electrical and Electronic Equipment Regulatory Regime (AHEEERR) yang ditandatangani pada tanggal 9 Desember 2005 di Kuala Lumpur, Malaysia oleh para Menteri Ekonomi ASEAN. Perjanjian ini mewajibkan setiap negara anggota ASEAN untuk mengharmoniskan dan menyinergiskan semua regulasi teknis yang terkait perdagangan produk kelistrikan dan elektronika dan berlaku di tingkat nasionalnya dengan ketentuan AHEEERR. Tujuan yang hendak dicapai ialah terwujudnya pergerakan arus barang/produk kelistrikan dan elektronika antar negara ASEAN melalui saling keberterimaan sertifikat hasil uji secara bebas dan mudah.

\section{KESIMPULAN}

Indonesia telah melakukan harmonisasi SNI berdasarkan kesepakatan ASEAN EE MRA, telah tersedia 118 SNI dari 119 standar yang disepakati, yang artinya sebanyak 99,15\% SNI telah harmonis dengan ASEAN Agreed Standard.

$>$ Ruang lingkup LPK yang terdaftar telah mencakup $26 \mathrm{SNI}$ wajib, dan masih akan terus bertambah seiring rencana LPK yang akan menambah ruang lingkup.

$>$ Proses listing $\mathrm{CAB}$ terdapat tahapan yang masih dapat ditingkatkan pelayanannya yaitu penerbitan sertifikat akreditasi dan lampirannya.

> Prinsip single undertaken merupakan titik kritis terwujudnya AHEEERR, mengingat belum semua anggota ASEAN meratifikasi AHEEERR.

> Dari uraian tersebut di atas dapat disimpulkan bahwa implemtasi ASEAN EE MRA terkait harmonisasi standar produk kelistrikan dan elektronika (EE) sudah efektif, sedangkan terkait saling pengakuan dan keberterimaan sertifikat hasil uji dan sertifikat produk EE antar negara anggota tidak efektif.

\section{UCAPAN TERIMAKASIH}

Penulis mengucapkan puji syukur kepada Allah SWT yang telah memberikan rahmat Nya sehingga dapat menyelesaikan penelitian ini, juga mengucapkan terima kasih kepada Kepala Pusat Penelitian dan Pengembangan Standardisasi (Puslitbang) serta rekan-rekan Peneliti BSN yang telah banyak memberikan masukan dan pandangan terhadap materi penelitian ini.

\section{DAFTAR PUSTAKA}

Arifin, Sjamsul dkk. (2008). Masyarakat Ekonomi ASEAN 2015. Jakarta : Alex Media Komputindo. ASEAN Secretariat. (2007) ASEAN Economic Community Blue Print. Jakarta.

ASEAN Secretariat. (2002). ASEAN EEE MRA Agreement. Jakarta. ASEAN Secretariat. (2014)

Bakhri, Boy S. (2015). Kesiapan Indonesia Menghadapi Masyarakat Ekonomi ASEAN 2015 Dari Perspektif Daya Saing Nasional. ISEI 
Baldwin (2005). Pengantar Ekonomi Industri: Pendekatan Struktur, Prilaku dan Kinerja Pasar. BPFE. Anggota IKAPI, Yogyakarta.

Bambang, Purwanggono, dkk. (2009). Pengantar Standardisasi Jakarta : Badan Standardisasi Nasional.

Budiman, Aida S. (2012) Masyarakat Ekonomi ASEAN: Konsep Masyarakat Ekonomi ASEAN. Work Paper Direktorat Internasional, Jakarta.

Badan Standardisasi Nasional (2016). Sistem Informasi Standar Nasional Indonesia (SISNI) 2016.

Badan Standardisasi Nasional. (2010). SNI Penguat Daya Saing Bangsa. Jakarta : BSN

Dedi. (2004) Dampak ASEAN Trade Facilitation terhadap Daya Saing Daerah. : Institut Pertanian Bogor.

Gibson, James L. et al. (1996). Organisasi: Perilaku, Struktur, Proses. Diterjemahkan oleh Ninuk Adriani. Jakarta: Binarupa Aksara.

Hidayat. 1996. Teori Efektifitas. Bandung. Angkasa
Iskandar. 2008. Metodologi Penelitian Pendidikan dan Sosial (Kuantitatif dan Kualitatif). Jakarta: GP Press.

Kementerian Perindustrian (2016) Ekspor Impor Indonesia, Kementerian Perindustrian

Kementerian Perdagangan Republik Indonesia. Statistik Perdagangan. Jakarta : Kementerian Perdagangan Republik Indonesia.

Muhammad Nukman Wijaya, 2012, Analisis Kebijakan Pasar Tunggal dan Basis Produksi ASEAN Produk Elektronik Terhadap Daya Saing Nasional, Studi Kasus Lampu Swaballast, Universitas Indonesia

Peraturan Menteri Perindustrian No. 86/MIND/PER/9/2009 tentang Standar Nasional Indonesia Bidang Industri.

Republik Indonesia, Undang-Undang No. 20 Tahun 2014 tentang Standardisasi dan Penilaian Kesesuaian.

Setiadi, Bambang. (2010) Nasionalisme di Era Globalisasi dengan Standar Nasional Indonesia (SNI). Jurnal Sekretariat Negara Republik Indonesia Negarawan

Tandjung, Marolop. (2011). Aspek dan Prosedur Ekspor - Impor. Jakarta : SalembavEmpat. 